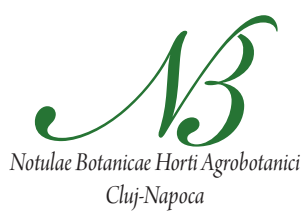

\title{
Evaluation of Genetic Diversity of Iranian Pomegranate Cultivars Using Fruit Morphological Characteristics and AFLP Markers
}

\author{
Zahra NEMATI*, Ali TEHRANIFAR, Mohammad FARSI, Amin \\ MIRSHAMSI KAKHKI, Hossein NEMATI, Mehdi KHAYAT \\ Ferdowsi University of Mashbad, Faculty of Agriculture, Center of Pomegranate Research, \\ Mashhad,Iran; zahra.nemati@rocketmail.com (corresponding author)
}

\begin{abstract}
The present research evaluated the diversity of a number of Iranian pomegranate cultivars using fruit morphological characteristics and AFLP markers. Thirty-one pomegranate cultivars were collected from Yazd Pomegranate Collection in Iran to study their diversity. Seven AFLP primer combinations were used to amplify a total of 112 polymorphic fragments (47.26\%). By use of AFLPs, a low genetic diversity level was detected among cultivars. The relationship between fruit characteristics was analyzed using the principal component analysis (PCA). The cluster analysis based on both fruit characteristics and AFLP data indicated that cultivars were not grouped according to their geographic origins. Moreover, the correlation between the diversity matrix based on fruit characteristics and Dice's genetic similarity coefficient was insignificant $(\mathrm{r}=0.06)$. The results obtained from this study can improve the conservation and management of pomegranate germplasm resources and could be helpful in optimizing breeding programs.
\end{abstract}

Keywords: AFLPs, fruit characteristics, genetic diversity, Iranian pomegranate, markers

\section{Introduction}

The pomegranate (Punica granatum L.), an ornamental plant which has been popular among Mediterranean peoples for centuries (Vazifeshenas et al., 2009) which is native to Iran and the Himalayas, produces delicious and edible fruits, and belongs to the Punicaceae family. There exists a local collection of pomegranate cultivars consisting of approximately 760 cultivars in the Yazd province of Iran (Behzadi Shahrbabaki, 1997).

Mars and Marrakchi (1999) reported that the fruit morphological characteristics are useful for pomegranate identification; however, these morphological traits are intensely dependent on the environmental conditions. There are some reports using RAPDs markers (Talebi Bodaff et al., 2003; Sarkhosh et al., 2006), SSR markers (Currò et al., 2010; Soriano et al., 2011), RAPDs and morphological markers (Sarkhosh et al., 2009; Zamani et al., 2007), as well as AFLPs markers (Jabir et al., 2008; Yuan et al., 2007) to analyze the genotypic characteristics and genetic relationships of pomegranate cultivars.

Due to the long history of Iranian pomegranate cultivation and the related vegetative propagation, several cases of homonymy and synonymy can be observed among this germplasm. Thus, it is essential to create a reliable classification system for Iranian pomegranates. Moreover, it is very important for using a sensitive and credible molecular technique to detect the DNA variation and identify the pomegranate germplasm, by helping breeders and nurserymen with the selection and propagation of a cultivar.
Having many advantages, such as reproducibility, high levels of polymorphism detection, genome-wide distribution of markers and no requirement for the previous knowledge of the studied genome, have caused AFLPs to be an appropriate technique for genetic diversity among the various molecular markers (Bruna et al., 2007; Polanco and Ruiz, 2002). In addition, Vos et al. (1995) reported that AFLP has been known as a more reliable technique than RFLP, RAPD.

AFLP markers have successfully been used to study the genetic diversity at the varietal level in many fruit trees, including apricot (Hurtado et al., 2002), olive (Rotondi et al., 2003) and pear (Bao et al., 2008). Despite, the various studies based on molecular markers in Iran, there is still ambiguities and debates about genetic diversity of pomegranate germplasm in Iran mainly due to different efficiency of different methods. Therefore, the aims of this project were to produce suitable markers for the characterization of pomegranate cultivars and to evaluate the diversity of Iranian pomegranate cultivars using fruit morphological characteristics and AFLPs markers.-

\section{Materials and methods}

\section{Plant materials}

Fruit and leaf samples of thirty one pomegranate genotypes were collected from adult trees from the pomegranate collection at Agricultural Research Center of Yazd, Iran (Tab. 1). 
262

Tab. 1. The name, peel color, aril color, taste and origin of 31 pomegranate cultivars

\begin{tabular}{|c|c|c|c|c|c|}
\hline No. & Cultivars & Peel color & Aril color & Taste & Origin \\
\hline 1 & 'Shirine Dane Sefide Ferdos' & Red & Red & Sweet & Khorasan \\
\hline 2 & 'Torshe shahvare Kashmar' & Red & Red & Sour & Khorasan \\
\hline 3 & 'Shishe Kab' & Red & Red & Sweet-sour & Khorasan \\
\hline 4 & 'Mazarie Bajestan' & Pink & Yellow & Sweet-sour & Khorasan \\
\hline 5 & 'Dom Anbaroti' & White & Yellow & Sour & Khorasan \\
\hline 6 & 'Shirine Dane Ghermeze Ferdos' & Pink & Red & Sweet & Khorasan \\
\hline 7 & 'Khazar Bajestani' & Red & Red & Sweet-sour & Khorasan \\
\hline 8 & 'Leili Post Nazok' & Red & Red & Sweet-sour & Khorasan \\
\hline 9 & 'Leili Post Koloft' & Pink & Yellow & Sweet-sour & Khorasan \\
\hline 10 & 'Torshe Shahvare Ferdos' & Red & Red & Sour & Khorasan \\
\hline 11 & 'Bazmanie Post Nazok' & Pink & Pink & Sweet-sour & Sistan o Balochestan \\
\hline 12 & 'Savehei Post Sefid' & white & Pink & Sweet-sour & Sistan o Balochestan \\
\hline 13 & 'Savehei Post Ghermez' & Pink & Yellow & Sweet-sour & Sistan o Balochestan \\
\hline 14 & 'Malase Porbare Saravan' & Pink & Pink & Sweet-sour & Sistan o Balochestan \\
\hline 15 & 'Malase Mamolie Sarjo' & Red & Red & Sweet-sour & Sistan o Balochestan \\
\hline 16 & 'Shekanare Post Koloff' & White & Pink & Sweet & Mazandaran \\
\hline 17 & 'Vahshie Janghalie Ghaemshahr' & Red & Yellow & Sweet-sour & Mazandaran \\
\hline 18 & 'Mahalie Parande Gorgan' & White & Red & Sour & Mazandaran \\
\hline 19 & 'Post Sefide Dezfol' & Red & Red & Sour & Khozestan \\
\hline 20 & 'Malase Dane Siyahe Ramhormoz' & White & Red & Sweet-sour & Khozestan \\
\hline 21 & 'Malase Post Sorkh' & Red & Red & Sweet-sour & Khozestan \\
\hline 22 & 'Shirine Post Ghermez' & Red & Red & Sweet & Azarbaejan \\
\hline 23 & 'Shirine Post Sefid' & Pink & Pink & Sweet & Azarbaejan \\
\hline 24 & 'Malase Post Nazok' & White & Yellow & Sweet-sour & Azarbaejan \\
\hline 25 & 'Zagh Yazdi' & Red & Red & Sour & Yazd \\
\hline 26 & 'Malase Yazdi' & Red & Red & Sweet-sour & Yazd \\
\hline 27 & 'Post Siyah' & Black & Yellow & Sweet & Yazd \\
\hline 28 & 'Gorje Shahvar' & Pink & Pink & Sweet & Yazd \\
\hline 29 & 'Agha Mohammadali' & Red & Red & Sweet & Markazi \\
\hline 30 & 'Alake Shirine Saveh' & Red & Red & Sweet & Markazi \\
\hline 31 & 'Malase Saveh' & Red & Red & Sweet-sour & Markazi \\
\hline
\end{tabular}

\section{Morphological and chemical fruit characteristics}

Quantitative and qualitative fruit characteristics were evaluated based on morphological and chemical analysis (Mars and Marakchi, 1999; Sarkhosh et al., 2009; Tehranifar et al., 2010), using 20 mature fruit samples per genotype (Tab. 2).

\section{DNA extraction and AFLP analysis}

Fresh and young fully expanded leaves from each cultivar were collected and ground in liquid nitrogen. Genomic DNA was extracted using DNeasy plant mini kits (Qiagen, Inc., CA, USA). The quantity and quality of isolated genomic DNA was determined using agarose gel $[1 \%(\mathrm{w} / \mathrm{v})]$ electrophoresis and a nano drop spectrophotometer (ND 1000, USA).

AFLP analysis was conducted using the minor modified standard procedure by Vos et al. (1995). Approximately 250 ng of genomic DNA was digested by restriction enzymes EcoRI and $M s e \mathrm{I}$ and then double standard adaptors were ligated to the obtained fragments to generate templates for amplification. The digest-Ligated DNA fragments were pre-amplified using EcoRI+1 (5'-GACTGCGTACCAATTCA-3') and Mse I+1 (5'-GATGAGTCCTGAGTAAC-3') primers under the following conditions: 20 cycles of $94^{\circ} \mathrm{C}$ for $30 \mathrm{~s}, 56^{\circ} \mathrm{C}$ for $60 \mathrm{~s}$ and $72^{\circ} \mathrm{C}$ for $60 \mathrm{~s}$ and then were used as templates (without dilution). Initially, a total of 35 primer combinations, from which seven primer combinations with the strongest and greatest number of bands were selected for AFLP reaction, were tested. Selective amplification was performed using a pair of $E c o \mathrm{RI}+3$ and $M s e I+3$ primers. The amplifications consisted of the following steps: one cycle of $94^{\circ} \mathrm{C}$ for $30 \mathrm{sec}, 65^{\circ} \mathrm{C}$ for $30 \mathrm{sec}$, and $72^{\circ} \mathrm{C}$ for $60 \mathrm{sec}$, followed by 13 cycles at decreasing annealing temperature in decrements of $0.7^{\circ} \mathrm{C}$ per cycle, then 23 cycles of $94^{\circ} \mathrm{C}$ for $30 \mathrm{sec}$, $56^{\circ} \mathrm{C}$ for $30 \mathrm{sec}$, and final extension $72^{\circ} \mathrm{C}$ for $60 \mathrm{sec}$. The amplification products were resolved by $6 \%$ denaturing polyacrylamid gels at 1200 volt for $120 \mathrm{~min}$ in $1 \mathrm{X}$ TBE (Tris-Borate Ethylenediaminetetraacetic acid). The AFLP markers were visualized by silver nitrate staining according to Sanguinetti et al. (1994). 


\section{Data analysis}

After normalizing quantitative morphological data, the mean values of each parameter were estimated for statistical analysis. The average values were utilized to calculate the principal component analysis (PCA) and cluster analysis based on the Euclidean distance between the different genotypes. The principal component analysis was used to compare the influence of each characteristic on the clustering of cultivars. Simply factors loading values equal or greater than 0.5 were considered significant. The dendrogram was conducted using Ward's methods via SPSS for the windows computer software (version, 16).

Tab. 2. List of fruit characteristic observed in the 31 pomegranate cultivars, range of variability, means and coefficient of variation

\begin{tabular}{|c|c|c|c|c|c|}
\hline $\begin{array}{l}\text { Trait } \\
\text { code }\end{array}$ & Trait & Min & Mean & $\operatorname{Max}$ & CV\% \\
\hline FW & Fruit weight (gr) & 194.38 & 243.90 & 314.52 & 11.60 \\
\hline FL & Fruit length $(\mathrm{mm})$ & 69.50 & 75.86 & 81.57 & 4.55 \\
\hline FD & Fruit diameter $(\mathrm{mm})$ & 64.99 & 78.97 & 86.88 & 5.18 \\
\hline $\mathrm{FL} / \mathrm{FD}$ & $\begin{array}{l}\text { Fruit length/ Fruit } \\
\text { diameter (Ratio) }\end{array}$ & 0.88 & 0.98 & 1.61 & 12.43 \\
\hline FV & Fruit volume (ml) & 204.25 & 262.49 & 341.36 & 11.63 \\
\hline FDe & Fruit Density $\left(\mathrm{gr} / \mathrm{cm}^{3}\right)$ & 0.68 & 0.93 & 0.9 & 2.76 \\
\hline $\mathrm{CL}$ & Calix length $(\mathrm{mm})$ & 13.45 & 19.53 & 24.0 & 12.73 \\
\hline $\mathrm{CD}$ & Calix diameter (mm) & 12.52 & 17.71 & 24.18 & 16.10 \\
\hline $\begin{array}{l}\mathrm{CL} / \\
\mathrm{CD}\end{array}$ & $\begin{array}{l}\text { Calix length/ Calix } \\
\text { diameter (Ratio) }\end{array}$ & 0.81 & 1.13 & 1.72 & 17.11 \\
\hline PT & Peel thickness (mm) & 3.13 & 4.12 & 6.51 & 19.01 \\
\hline PW & Peel weight (gr) & 63.61 & 114.81 & 185.14 & 21.60 \\
\hline $\mathrm{PW} / \mathrm{F}$ & Peel weight / Fruit (\%) & 32.72 & 47.21 & 75.18 & 18.69 \\
\hline AW & Aril weight (gr) & 64.48 & 125.25 & 170.43 & 19.81 \\
\hline $\mathrm{AL}$ & Aril length (mm) & 11.29 & 11.97 & 13.17 & 4.26 \\
\hline $\mathrm{AD}$ & Aril diameter $(\mathrm{mm})$ & 6.49 & & & 5.84 \\
\hline $\begin{array}{l}\mathrm{AL} / \\
\mathrm{AD}\end{array}$ & $\begin{array}{l}\text { Aril length/ Aril } \\
\text { diameter (Ratio) }\end{array}$ & 1.40 & 1.61 & 1.79 & 5.57 \\
\hline $\mathrm{A} / \mathrm{F}$ & Aril/Fruit (\%) & 26.29 & 51.26 & 65.81 & 16.28 \\
\hline SW & Seed weight (gr) & 21.23 & 33.74 & 59.59 & 25.89 \\
\hline $\mathrm{SW} / \mathrm{F}$ & Seed weight/ Fruit (\%) & 9.45 & 13.82 & 20.56 & 20.75 \\
\hline $\mathrm{JV}$ & Juice volume (ml) & 37.28 & 82.17 & 112.50 & 20.84 \\
\hline JW & Juice weight(gr) & 39.31 & 86.41 & 117.75 & 20.95 \\
\hline JD & Juice density $\left(\mathrm{gr} / \mathrm{cm}^{3}\right)$ & 1.03 & 1.05 & 1.06 & 0.81 \\
\hline $\mathrm{J} / \mathrm{F}$ & Juice/Fruit (\%) & 16.06 & 35.43 & 47.15 & 18.85 \\
\hline $\mathrm{PH}$ & $\mathrm{pH}$ & 2.87 & 3.65 & 4.21 & 9.29 \\
\hline TSS & Total soluble solids (\%) & 11.0 & 13.62 & 15.38 & 8.21 \\
\hline TA & Titrable acidity (\%) & 0.33 & 1 & 2.44 & 52.98 \\
\hline MI & Maturity index(-) & 5.03 & 18.12 & 47.07 & 56.78 \\
\hline $\mathrm{AC}$ & $\begin{array}{c}\text { Ascorbic } \\
\operatorname{acid}(\mathrm{mg} / 100 \mathrm{~g})\end{array}$ & 7.19 & 13.76 & 18.42 & 22.20 \\
\hline ANA & $\begin{array}{c}\text { Anthocyanin } \\
\text { absorbance }\left(\mathrm{O}^{-\mathrm{D}_{510}}\right)\end{array}$ & 5.55 & 9.60 & 30.12 & 58.10 \\
\hline AN & Antioxcidant (\%) & 15.98 & 30.06 & 54.37 & 33.04 \\
\hline JTP & $\begin{array}{l}\text { Juice total phenol } \\
(\mathrm{mg} / 100 \mathrm{~g})\end{array}$ & 159.79 & 3301.84 & 3195.33 & 83.14 \\
\hline TS & Total sugar $(\mathrm{mg} / 100 \mathrm{~g})$ & 13.23 & 18.68 & 21.72 & 9.69 \\
\hline
\end{tabular}

${ }^{*} \mathrm{CV}$, coefficient of variation $=($ standard deviation $/$ mean $) \times 100$
Manually, AFLP fragments were scored according to their presence (1) or absence (0) to form a raw data matrix. The statistical analysis was constructed using the NTSYS software version 2.02 (Roholf, 1998). The genetic similarities between all cultivars were estimated based on the Dice's coefficient (Nei and Li, 1979). In order to construct a dendrogram, the similarity matrix was calculated by the unweighted pair-group method of the arithmetic average (UPGMA) using the SAHN clustering model. The cophenetic coefficient was computed in order to test the goodness of fit between the cluster in the dendrogram and the similarity coefficient matrix. The Mantel test was applied to calculate the correlation between the two dendrograms produced by morphological and AFLP data (Mantel, 1967).

\section{Results and discussion}

\section{Fruit characteristics}

Thirty-one cultivars were characterized by a large variability in quantitative morphological traits including fruit shape, color and juice (data not shown).The range of the mean values of each studied cultivar exhibited a significant diversity in the fruit characteristics. The mean, maximum, minimum and coefficient of the variation values for each characteristic among all genotypes were illustrated in Tab. 2. Among all quantitative characteristics titratable acidity (TA), Juice total phenol (JTP) and Anthocyanin absorbance (ANA) showed higher CV values indicating a high level of variation. PCA results indicated that the first component related to fruit weight (FW), fruit length (FL), fruit volume (FV), peel thickness (PT), peel weight/ fruit (PW/F ratio), aril weight (AW), aril length $(\mathrm{AL})$, aril diameter $(\mathrm{AD})$, aril length/aril diameter (AL/AD ratio), aril/fruit (A/F ratio), seed weight (SW), juice volume (JV), juice density (JD), juice/Fruit (J/F ratio), total sugar (TS) and total soluble solids (TSS) accounted for $31.84 \%$ of the total variation and grouped cultivars based on most of the studied physical characteristics. The second component which explained $19.24 \%$ of the total variation is dominated by five other physical characteristics explaining 95.01 of the total variance (Tab. 3). According to the aforementioned seven factors, thirty-one cultivars fall into the main five clusters at a distance of 10 (Fig. 1).

\section{AFLP analysis}

A total 112 polymorphic bands from 237 fragments, ranging in size from 50 to $800 \mathrm{bp}$, were generated using seven primer combinations (Fig. 2). The percentage of polymorphic DNA bands ranged from $40 \%$ (E-ACT, MCTT) to $58.06 \%$ (E-AAC, M-CAA) with an average of $47.26 \%$ (Tab. 4).

The range of the similarity matrix obtained by the Dice coefficient varied between 0.793 and 0.997 with an average of 0.944 (Tab. 5). The genetic relationship between 31 cultivars based on the Dice's similarity coefficient is shown 


Dom Anbaroti
Leili Post Koloft
Bazmanie Post Nazok
Shekanare Post Koloft
Vahshie Janghalie Ghaemshahr
Malase Post Nazok
Torshe Shahvare Ferdos
Savehei Post Ghermez
Malase Yazdi
Shirine Post Ghermez
Zagh Yazdi
Shishe Kab
Malase Post Sorkh
Shirine Dane Sefide Ferdos
Mahalie Parande Gorgan
Post Sefide Dezfol
Malase Dane Siyahe Ramhormoz
Shirine Post Sefid
Alake Shirine Saveh
Shirine Dane Ghermeze Ferdos
Leili Post Nazok
Post Siyah
Agha Mohammadali
Savehei Post Sefid
Malase Mamolie Sarjo
Torshe shahvare Kashmar
Mazarie Bajestan
Khazar Bajestani
Malase Porbare Saravan
Malase Saveh
Gorje Shahvar

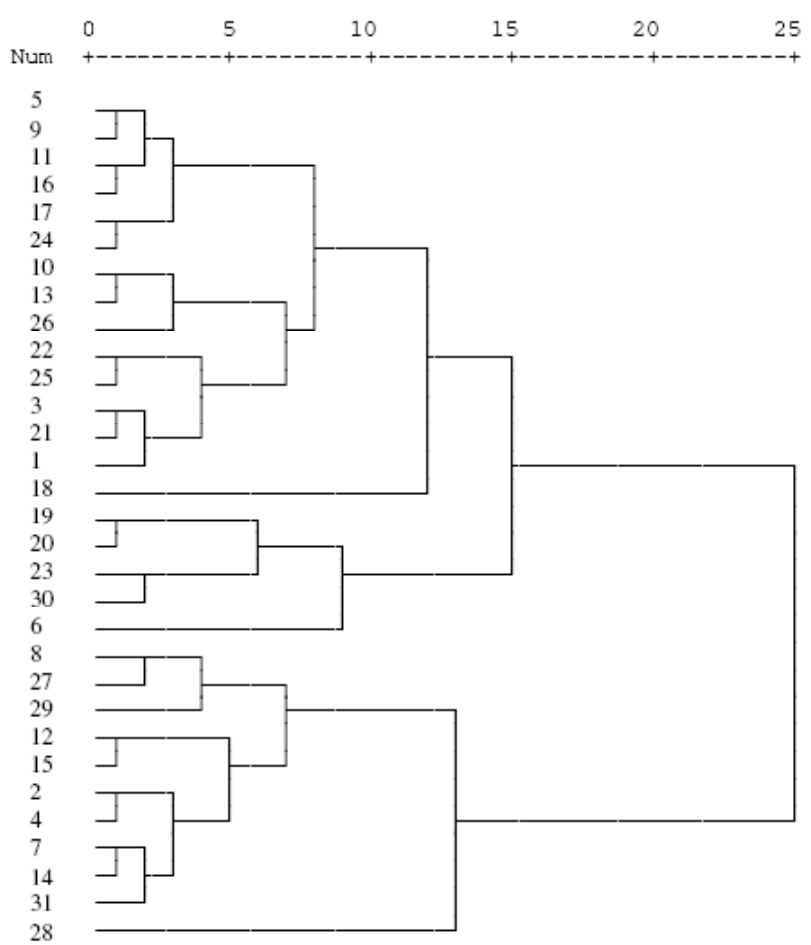

Fig. 1. The principle component analysis dendrogram of 31 pomegranate cultivars obtained from fruit characteristics data

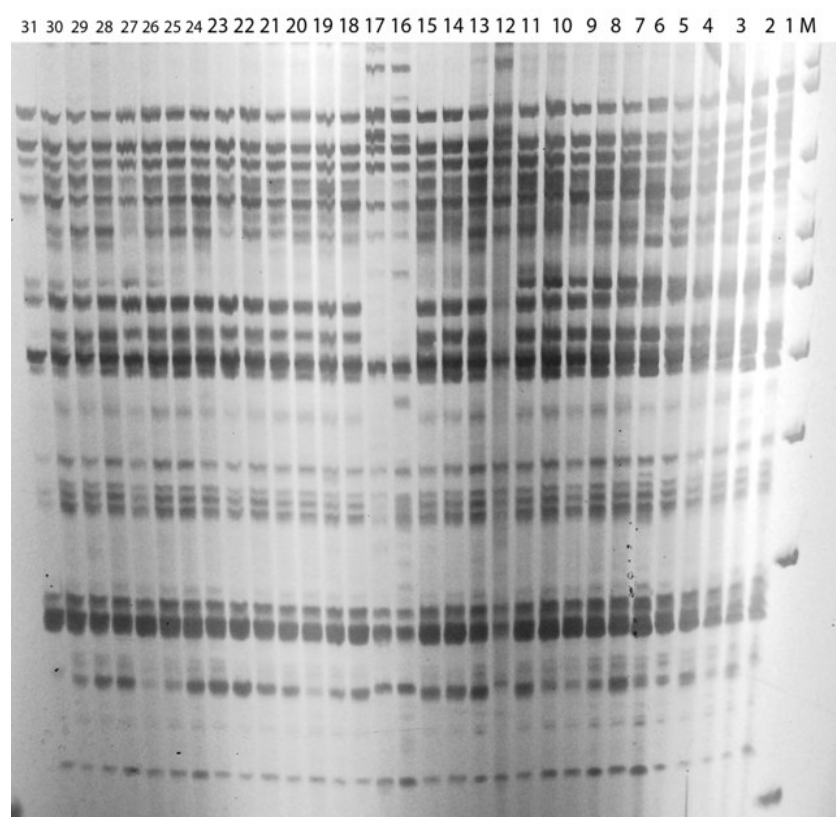

Fig. 2. An example of AFLP profile using the E-ACT / M-CAA selective primer combination. $\mathrm{M}$ is $50 \mathrm{bp}$ standard sizes Marker

in a dendrogram (Fig. 3). The cophenetic correlation coefficient calculated between the similarity matrix and cophenetic matrix, which were obtained from dendrogram data, was very high $(r=0.99)$. According to Dice's similarity matrix and the UPGMA clustering method, the dendrogram exhibited two main groups (A-B) that were identified at the 0.81 similarity level (Fig. 3). Group A consisted of two subgroups, one containing the cultivar No. 5 that was identified at the 0.90 similarity level and the other, including two cultivars (No. 4 and No. 7) and showed the morphological relationship. Group B contained all other 28 cultivars, which were identified at the 0.92 similarity level. Twenty-eight morphologically distinct cultivars are completely close to one another in the genetic analysis by AFLPs. Except for the three cultivars (No. 4, No. and No. 7 ), which were separated by a similarity coefficient of 0.81 , most of them had a similarity coefficient up to 0.95 . No obvious relationships were detected between the morphology, the origins and the estimated genetic traits. According to the genetic analysis conducted by AFLP, most of the cultivars were composed of simply one group in spite of their distinct origin and morphology. The three remaining cultivars, which did not fall into this group, were morphologically distinct. According to the dendrogram (Fig. 3 ) and similarity matrix (Tab. 5), a relatively low genetic diversity was observed among the studied cultivars.

In this study, both dendrograms obtained from the morphological and AFLP markers were not consistent with the local name and geographical origin. Furthermore, the results of this study were in agreement with the others (Jabir et al., 2008; Narzary et al., 2009; Yuan et al., 2007), showing that the clustering of the cultivars is not related to the geographical distance.

The level of the genetic diversity highly correlated with the sample size; therefore, it would be worth mentioning that the used sample size was small in the present study. Also, another reason for the low genetic diversity could be due to the vegetative propagation. Over a period of 2500 years (Behzadi Shahrbabaki, 1997), there has been more 
Tab. 3. Eigen values, cumulative variance and factor loadings for each variable of the components of PCA analysis for 31 pomegranate cultivars

\begin{tabular}{|c|c|c|c|c|c|c|c|}
\hline Factor & 1 & 2 & 3 & 4 & 5 & 6 & 7 \\
\hline Eigen value & 11.13 & 6.74 & 4.86 & 3.78 & 2.83 & 2.23 & 1.69 \\
\hline \%of variance & 31.81 & 19.24 & 13.89 & 10.80 & 8.07 & 6.37 & 4.82 \\
\hline $\begin{array}{l}\text { Cumulative } \\
\text { variance }\end{array}$ & 31.81 & 51.06 & 64.94 & 75.74 & 83.82 & 90.19 & 95.01 \\
\hline Characteristics & & & Factor & Loading & & & \\
\hline Fruit weight & $0.72^{\circ}$ & 0.28 & $0.54^{\circ}$ & 0.03 & -0.15 & 0.17 & 0.07 \\
\hline Fruit length & 0.76 & 0.46 & 0.20 & -0.09 & -0.02 & 0.31 & 0.08 \\
\hline Fruit diameter & 0.12 & -0.33 & -0.02 & -0.86 & -0.28 & 0.15 & -0.16 \\
\hline $\begin{array}{l}\text { Fruit length/ } \\
\text { Fruit diameter }\end{array}$ & 0.23 & $0.53^{\circ}$ & 0.15 & 0.76 & 0.24 & 0.00 & 0.11 \\
\hline Fruit volume & $0.70^{\circ}$ & 0.39 & $0.51^{\circ}$ & -0.13 & -0.17 & 0.16 & 0.03 \\
\hline Fruit Density & 0.17 & $-0.54^{\circ}$ & 0.10 & $0.74^{\circ}$ & 0.07 & 0.16 & 0.20 \\
\hline Calix length & 0.35 & $0.63^{\circ}$ & 0.42 & -0.41 & -0.13 & 0.05 & 0.31 \\
\hline Calix diameter & -0.41 & -0.33 & 0.47 & -0.01 & $0.59^{\circ}$ & -0.37 & -0.05 \\
\hline $\begin{array}{l}\text { Calix length/ } \\
\text { Calix diameter }\end{array}$ & 0.49 & $0.55^{\circ}$ & -0.11 & -0.29 & -0.46 & 0.28 & 0.26 \\
\hline Peel thickness & $-0.75^{\circ}$ & 0.22 & 0.45 & 0.20 & 0.27 & 0.15 & 0.24 \\
\hline Peel weight & -0.48 & $0.61^{\circ}$ & $0.52^{\circ}$ & 0.05 & -0.04 & 0.26 & 0.09 \\
\hline $\begin{array}{c}\text { Peel weight / } \\
\text { Fruit }\end{array}$ & $-0.87^{\circ}$ & 0.41 & 0.22 & -0.01 & 0.04 & 0.16 & 0.06 \\
\hline Aril weight & $0.99^{\circ}$ & -0.12 & 0.11 & -0.00 & -0.05 & -0.02 & 0.01 \\
\hline Aril length & $0.88^{\circ}$ & -0.37 & -0.23 & 0.01 & 0.03 & -0.12 & -0.06 \\
\hline Aril diameter & $0.78^{\circ}$ & 0.43 & -0.04 & 0.27 & 0.08 & 0.31 & -0.06 \\
\hline $\begin{array}{l}\text { Aril length/Aril } \\
\text { diameter }\end{array}$ & 0.64 & 0.35 & -0.39 & 0.34 & 0.16 & 0.30 & -0.12 \\
\hline Aril/Fruit & $0.91^{\circ}$ & -0.34 & 0.14 & -0.07 & -0.08 & -0.10 & -0.02 \\
\hline Seed weight & $0.90^{\circ}$ & -0.36 & 0.15 & -0.06 & -0.07 & -0.10 & 0.01 \\
\hline $\begin{array}{l}\text { Seed weight/ } \\
\text { Fruit }\end{array}$ & 0.21 & -0.48 & 0.49 & 0.16 & 0.22 & -0.09 & 0.56 \\
\hline Juice volume & $0.75^{\circ}$ & $-0.60^{\circ}$ & -0.14 & -0.06 & 0.01 & -0.22 & -0.05 \\
\hline Juice weight & 0.08 & 0.74 & 0.11 & -0.19 & 0.40 & -0.06 & -0.49 \\
\hline Juice density & -0.56 & $0.68^{\circ}$ & -0.27 & -0.17 & 0.18 & -0.11 & -0.23 \\
\hline Juice/Fruit & $0.78^{\circ}$ & -0.01 & 0.46 & -0.04 & 0.19 & 0.05 & -0.26 \\
\hline $\mathrm{pH}$ & 0.45 & 0.37 & $-0.54^{\circ}$ & 0.16 & -0.21 & -0.03 & -0.31 \\
\hline $\begin{array}{l}\text { Total soluble } \\
\text { solids }\end{array}$ & $0.58^{\circ}$ & -0.07 & -0.56 & -0.04 & 0.37 & -0.28 & 0.33 \\
\hline Titrable acidity & -0.29 & $-0.69^{\circ}$ & -0.19 & -0.01 & 0.01 & $0.57^{\circ}$ & 0.01 \\
\hline Maturity index & 0.31 & $0.75^{\circ}$ & -0.07 & 0.45 & 0.14 & -0.31 & 0.02 \\
\hline Ascorbic acid & 0.01 & 0.06 & $-0.67^{\circ}$ & $0.65^{\circ}$ & -0.13 & 0.17 & 0.09 \\
\hline $\begin{array}{c}\text { Anthocyanin } \\
\text { absorbance }\end{array}$ & 0.24 & 0.28 & $-0.84^{\circ}$ & -0.24 & 0.20 & -0.03 & 0.23 \\
\hline Antioxcidant & -0.08 & $-0.55^{\circ}$ & 0.10 & -0.01 & 0.46 & 0.4 & -0.32 \\
\hline $\begin{array}{l}\text { Juice } \\
\text { phenol }\end{array}$ & 0.41 & -0.43 & 0.44 & 0.12 & 0.31 & 0.38 & -0.12 \\
\hline Total sugar & $-0.62^{\circ}$ & -0.28 & -0.30 & 0.02 & $-0.52^{\circ}$ & 0.14 & 0.26 \\
\hline Aril color & -0.14 & -0.12 & $0.51^{\circ}$ & 0.26 & $-0.71^{\circ}$ & -0.28 & -0.14 \\
\hline Peel color & -0.01 & -0.11 & 0.35 & $0.52^{\circ}$ & -0.46 & $-0.50^{\circ}$ & -0.29 \\
\hline Taste & 0.30 & 0.29 & 0.12 & -0.49 & 0.33 & -0.47 & 0.33 \\
\hline
\end{tabular}

possibility that an intensive exchange of propagation material, such as cutting, all around provinces of Iran. Also, it is assumed that a large proportion of valuable cultivated pomegranates have lost through the continuous removal of old plantations, and commercially seedlings propagated from a few cultivars by cuttings. As a low level of polymorphism detected by SSR markers in pomegranate
Tab. 4. AFLP primer combinations, total numbers of fragments generated by each primer set, number of polymorphic fragments detected, and percentages of polymorphic fragments used in this study of 31 pomegranate cultivars

\begin{tabular}{|c|c|c|c|}
\hline Primer & $\begin{array}{l}\text { Total no. } \\
\text { of bands }\end{array}$ & $\begin{array}{c}\text { No of } \\
\text { polymorphic } \\
\text { bands }\end{array}$ & $\begin{array}{c}\% \text { of } \\
\text { polymorphic } \\
\text { bands }\end{array}$ \\
\hline $\mathrm{EACT}+/ \mathrm{M}+\mathrm{CAA}$ & 37 & 21 & 56.76 \\
\hline $\mathrm{EACT}+/ \mathrm{M}+\mathrm{CTT}$ & 30 & 12 & 40 \\
\hline $\mathrm{EACT}+/ \mathrm{M}+\mathrm{CCT}$ & 40 & 18 & 45 \\
\hline $\mathrm{EACT}+/ \mathrm{M}+\mathrm{CTA}$ & 32 & 14 & 43.75 \\
\hline $\mathrm{EACC}+/ \mathrm{M}+\mathrm{CAA}$ & 32 & 13 & 40.62 \\
\hline $\mathrm{E} \mathrm{AAC}+/ \mathrm{M}+\mathrm{CAA}$ & 31 & 18 & 58.06 \\
\hline $\mathrm{EAAC}+/ \mathrm{M}+\mathrm{CTT}$ & 35 & 16 & 45.71 \\
\hline Total & 237 & 112 & \\
\hline Average & 33.8 & 16 & 47.26 \\
\hline
\end{tabular}

genotypes (Currò et al., 2010), these Authors reported that higher levels of polymorphism could be detected by analyzing larger collections or natural populations in the origin areas.

A very poor correlation was obtained between the morphological distance matrix and AFLP similarities matrix $(\mathrm{r}=0.06)$ (Fig. 4). This result was in agreement with the results obtained by Talebi Boddaf et al. (2003), Zamani et al. (2007) and Sarkhosh et al. (2009) and confirmed the insignificant correlation between the morphology and the RAPD markers. In order to provide a better matching of the relationship between the morphological traits and the molecular markers, more morphological characteristics such as phenological traits of leaves, flowers and fruits are required to be estimated.

The first possible explanation for the lack of correspondence between morphological traits and molecular markers are that these morphological differences such as the fruit color, fruit shape, height, form of trees and branching habit are probably the result of alleles that were not detected by the present molecular markers. Wen et al. (2004) and Zahuang et al. (2004) proposed that posttranscriptional effects, translation, environmental changes and non-nuclear inheritance can lead to the lack of the correspondence between morphological traits and molecular marker. In some studies the low correlation between these markers are observed (Heidary et al., 2009; Martinez, 2003; Rotondi et al., 2003) and the others (Cavagnaro et al., 2006) it has been showed that there is a significant correlation between these markers. Another explanation would be the relatively low number of markers used in this study resulted in inadequate genome coverage (De Langhe et al., 2005).

To prepare a better matching of the relationship between morphological and molecular markers, more primers or an extended set of primer combinations must be utilized. More studies with both morphological and other markers such as Co-dominate markers, might solve this issue.

In conclusion, the results demonstrated that AFLP profiles are valuable tools with great potential for classi- 
Tab. 5. Genetics similarity matrix among 31 Persian pomegranate cultivars based on AFLP data

\begin{tabular}{|c|c|c|c|c|c|c|c|c|c|c|c|c|c|c|c|c|c|c|c|c|c|c|c|c|c|c|c|c|c|c|c|}
\hline & 1 & 2 & 3 & 4 & 5 & 6 & 7 & 8 & 9 & 10 & 11 & 12 & 13 & 14 & 15 & 16 & 17 & 18 & 19 & 20 & 21 & 22 & 23 & 24 & 25 & 26 & 27 & 28 & 29 & 30 & 31 \\
\hline 1 & 1 & & & & & & & & & & & & & & & & & & & & & & & & & & & & & & \\
\hline 2 & 0.989 & 1 & & & & & & & & & & & & & & & & & & & & & & & & & & & & & \\
\hline 3 & 0.997 & 0.986 & 1 & & & & & & & & & & & & & & & & & & & & & & & & & & & & \\
\hline 4 & 0.809 & 0.815 & 0.806 & 1 & & & & & & & & & & & & & & & & & & & & & & & & & & & \\
\hline 5 & 0.805 & 0.812 & 0.803 & 0.907 & 1 & & & & & & & & & & & & & & & & & & & & & & & & & & \\
\hline 6 & 0.991 & 0.980 & 0.994 & 0.806 & 0.809 & 1 & & & & & & & & & & & & & & & & & & & & & & & & & \\
\hline 7 & 0.812 & 0.813 & 0.815 & 0.913 & 0.896 & 0.815 & 1 & & & & & & & & & & & & & & & & & & & & & & & & \\
\hline 8 & 0.983 & 0.971 & 0.986 & 0.797 & 0.804 & 0.986 & 0.811 & 1 & & & & & & & & & & & & & & & & & & & & & & & \\
\hline 9 & 0.986 & 0.974 & 0.989 & 0.805 & 0.797 & 0.983 & 0.809 & 0.991 & 1 & & & & & & & & & & & & & & & & & & & & & & \\
\hline 10 & 0.975 & 0.969 & 0.977 & 0.819 & 0.822 & 0.972 & 0.828 & 0.974 & 0.972 & 1 & & & & & & & & & & & & & & & & & & & & & \\
\hline 11 & 0.980 & 0.975 & 0.983 & 0.802 & 0.815 & 0.983 & 0.822 & 0.986 & 0.977 & 0.978 & 1 & & & & & & & & & & & & & & & & & & & & \\
\hline 12 & 0.977 & 0.971 & 0.980 & 0.809 & 0.816 & 0.980 & 0.817 & 0.977 & 0.974 & 0.963 & 0.974 & 1 & & & & & & & & & & & & & & & & & & & \\
\hline 13 & 0.977 & 0.972 & 0.980 & 0.815 & 0.812 & 0.986 & 0.813 & 0.977 & 0.980 & 0.969 & 0.980 & 0.971 & 1 & & & & & & & & & & & & & & & & & & \\
\hline 14 & 0.991 & 0.980 & 0.989 & 0.805 & 0.802 & 0.983 & 0.809 & 0.991 & 0.994 & 0.972 & 0.977 & 0.974 & 0.974 & 1 & & & & & & & & & & & & & & & & & \\
\hline 15 & 0.986 & 0.980 & 0.989 & 0.805 & 0.808 & 0.983 & 0.820 & 0.991 & 0.988 & 0.983 & 0.983 & 0.974 & 0.974 & 0.988 & 1 & & & & & & & & & & & & & & & & \\
\hline 16 & 0.971 & 0.966 & 0.974 & 0.809 & 0.811 & 0.974 & 0.812 & 0.977 & 0.980 & 0.969 & 0.980 & 0.971 & 0.977 & 0.974 & 0.974 & 1 & & & & & & & & & & & & & & & \\
\hline 17 & 0.986 & 0.974 & 0.989 & 0.801 & 0.809 & 0.983 & 0.821 & 0.986 & 0.983 & 0.983 & 0.989 & 0.980 & 0.969 & 0.983 & 0.989 & 0.974 & 1 & & & & & & & & & & & & & & \\
\hline 18 & 0.980 & 0.974 & 0.983 & 0.806 & 0.803 & 0.977 & 0.815 & 0.986 & 0.989 & 0.983 & 0.989 & 0.968 & 0.980 & 0.983 & 0.989 & 0.986 & 0.989 & 1 & & & & & & & & & & & & & \\
\hline 19 & 0.986 & 0.974 & 0.989 & 0.805 & 0.802 & 0.989 & 0.809 & 0.986 & 0.988 & 0.966 & 0.983 & 0.980 & 0.986 & 0.983 & 0.977 & 0.986 & 0.977 & 0.983 & 1 & & & & & & & & & & & & \\
\hline 20 & 0.971 & 0.960 & 0.974 & 0.808 & 0.793 & 0.968 & 0.805 & 0.971 & 0.974 & 0.963 & 0.963 & 0.965 & 0.966 & 0.968 & 0.974 & 0.965 & 0.974 & 0.974 & 0.968 & 1 & & & & & & & & & & & \\
\hline 21 & 0.983 & 0.977 & 0.986 & 0.803 & 0.811 & 0.986 & 0.812 & 0.983 & 0.980 & 0.969 & 0.980 & 0.994 & 0.977 & 0.980 & 0.980 & 0.971 & 0.986 & 0.974 & 0.980 & 0.971 & 1 & & & & & & & & & & \\
\hline 22 & 0.974 & 0.969 & 0.977 & 0.806 & 0.814 & 0.983 & 0.815 & 0.986 & 0.977 & 0.977 & 0.983 & 0.974 & 0.991 & 0.977 & 0.983 & 0.974 & 0.977 & 0.983 & 0.977 & 0.968 & 0.980 & 1 & & & & & & & & & \\
\hline 23 & 0.989 & 0.983 & 0.991 & 0.809 & 0.805 & 0.986 & 0.817 & 0.988 & 0.991 & 0.980 & 0.980 & 0.977 & 0.977 & 0.991 & 0.997 & 0.977 & 0.986 & 0.986 & 0.980 & 0.971 & 0.983 & 0.980 & 1 & & & & & & & & \\
\hline 24 & 0.983 & 0.977 & 0.986 & 0.808 & 0.804 & 0.980 & 0.816 & 0.988 & 0.991 & 0.980 & 0.980 & 0.971 & 0.977 & 0.986 & 0.997 & 0.977 & 0.986 & 0.991 & 0.980 & 0.977 & 0.977 & 0.980 & 0.994 & 1 & & & & & & & \\
\hline 25 & 0.974 & 0.968 & 0.977 & 0.805 & 0.813 & 0.977 & 0.809 & 0.974 & 0.977 & 0.960 & 0.977 & 0.968 & 0.980 & 0.971 & 0.971 & 0.991 & 0.966 & 0.977 & 0.988 & 0.962 & 0.968 & 0.971 & 0.974 & 0.974 & 1 & & & & & & \\
\hline 26 & 0.914 & 0.909 & 0.917 & 0.811 & 0.819 & 0.917 & 0.820 & 0.925 & 0.923 & 0.924 & 0.929 & 0.914 & 0.926 & 0.917 & 0.923 & 0.926 & 0.917 & 0.929 & 0.929 & 0.907 & 0.914 & 0.923 & 0.920 & 0.925 & 0.923 & 1 & & & & & \\
\hline 27 & 0.945 & 0.939 & 0.948 & 0.810 & 0.807 & 0.948 & 0.824 & 0.962 & 0.959 & 0.943 & 0.960 & 0.957 & 0.957 & 0.953 & 0.959 & 0.962 & 0.954 & 0.960 & 0.959 & 0.950 & 0.957 & 0.960 & 0.957 & 0.962 & 0.965 & 0.916 & 1 & & & & \\
\hline 28 & 0.983 & 0.977 & 0.986 & 0.803 & 0.811 & 0.986 & 0.812 & 0.977 & 0.980 & 0.969 & 0.986 & 0.977 & 0.983 & 0.974 & 0.980 & 0.983 & 0.980 & 0.980 & 0.986 & 0.971 & 0.983 & 0.974 & 0.983 & 0.983 & 0.986 & 0.920 & 0.957 & 1 & & & \\
\hline 29 & 0.980 & 0.974 & 0.983 & 0.817 & 0.809 & 0.977 & 0.821 & 0.974 & 0.983 & 0.983 & 0.977 & 0.974 & 0.974 & 0.977 & 0.983 & 0.986 & 0.983 & 0.989 & 0.983 & 0.968 & 0.974 & 0.971 & 0.986 & 0.986 & 0.977 & 0.929 & 0.954 & 0.980 & 1 & & \\
\hline 30 & 0.994 & 0.983 & 0.997 & 0.810 & 0.807 & 0.991 & 0.818 & 0.983 & 0.986 & 0.980 & 0.986 & 0.977 & 0.977 & 0.986 & 0.986 & 0.977 & 0.991 & 0.986 & 0.986 & 0.971 & 0.983 & 0.974 & 0.989 & 0.983 & 0.974 & 0.920 & 0.945 & 0.983 & 0.986 & 1 & \\
\hline 31 & 0.983 & 0.977 & 0.986 & 0.810 & 0.807 & 0.980 & 0.818 & 0.983 & 0.986 & 0.980 & 0.980 & 0.971 & 0.972 & 0.986 & 0.991 & 0.977 & 0.986 & 0.986 & 0.974 & 0.966 & 0.977 & 0.974 & 0.994 & 0.989 & 0.968 & 0.920 & 0.951 & 0.977 & 0.986 & 0.989 & 1 \\
\hline
\end{tabular}




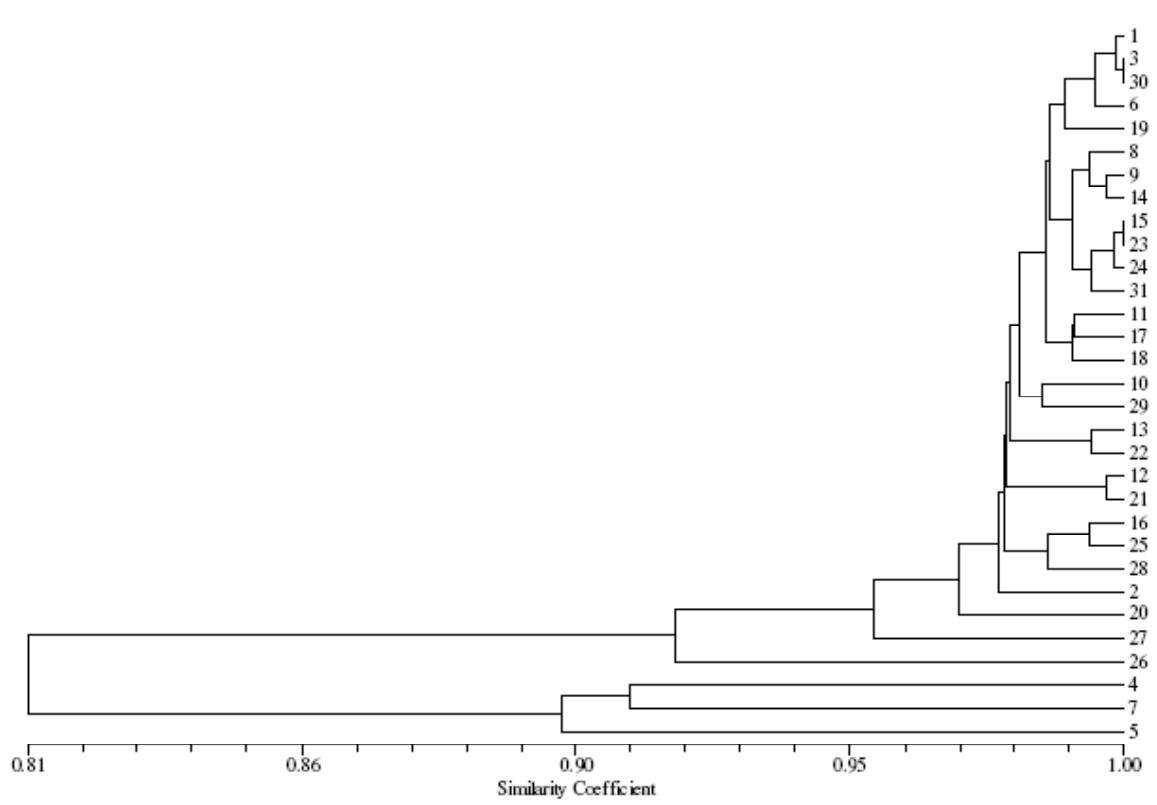

Shirine Dane Sefide Ferdos Shishe Kab

Alake Shirine Saveh Shirine Dane Ghermeze Ferdos Post Sefide Dezfol Leili Post Nazok Leili Post Koloft Malase Porbare Saravan Malase Mamolie Sarjo Shirine Post Sefid Malase Post Nefid Malase Saveh

Bazmanie Post Nazok Vahshie Janghalie Ghaemshahr Mahalie Parande Gorgan Torshe Shahvare Ferdos Agha Mohammadali Savehei Post Ghermez Shirine Post Gherme Savehei Post Sefid Malase Post Sorkh Shekanare Post Koloft Zagh Yazdi Gorje Shahvar Torshe shahvare Kashmar Malase Dane Siyahe Ramhormoz Post Siyah Mazarie Bajestan Khazar Bajestan Dom Anbaroti

Simikrity Coefficient

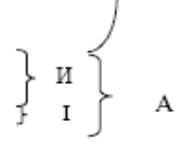

Fig. 3. UPGMA dendrogram constructed using the Dice's similarity (Nei and Li, 1979) coefficient analysis based on molecular profiles revealed by AFLP marker

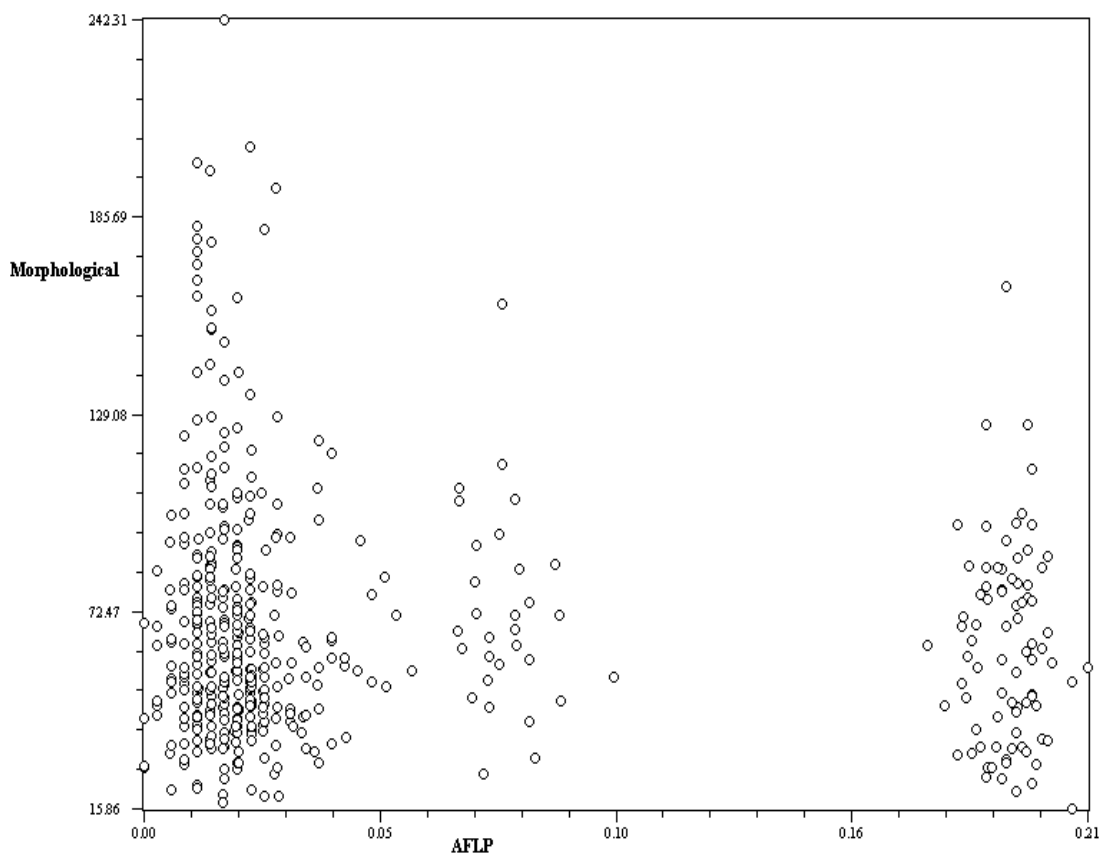

Fig. 4. Scatter plots showing pair wise comparisons between the Dice's similarity coefficients (Nei and Li, 1979) as calculated from AFLP analysis and distance using fruit characteristics

fications of Iranian pomegranate. In addition, complete comprehension of the genetic diversity within cultivars would contribute to a more efficient use of germplasm in plant breeding programs. Furthermore, it is essential to investigate other molecular markers linked closely to the morphological traits of pomegranate in the future.

\section{Acknowledgements}

The authors thank Agricultural Research Center of the Yazd province for plant material supply and Institute of
Zist-Fanavari of Ferdowsi University of Mashhad for financial support.

\section{References}

Bao L, Chen K, Zhang D, Li X, Teng Y (2008). An assessment of genetic variability and relationships within Asian pears based on AFLP (amplified fragment length polymorphism) markers. Sci Hortic 116:374-380.

Behzadi Shahrbabaki H (1997). Genetic diversity of pomegranate genotypes in Iran. Agriculture Education Pub. 
268

Karaj, Iran, 265 p (In Farsi).

Bruna S, Portis E, Cervelli C, De Benedetti L, Schiva T, Mercuri A (2007). AFLP-based genetic relationships in the Mediterranean myrtle (Myrtus communis L.). Sci Hortic 113:370-375.

Cavagnaro PF, Cavagnaro JB, Lemes JL, Masuelli RW, Passera CB (2006. Genetic diversity among varieties of the native forage grass Trichloris crinita based on AFLP markers, morphological characters, and quantitative agronomic traits. Genome 49(8):906-918.

Currò S, Caruso M, Distefano G, Gentile A, La Malfa S (2010). New microsatellite loci for pomegranate, Punica granatum (Lythraceae). Am J Bot 97:58-60.

De Langhe E, Pillay M, Tenkouano A, Swennen R (2005). Integrating morphological and molecular taxonomy in Musa: the African plantains (Musa spp. AAB group). Plant System Evol 255:225-236.

Jbir R, Hasanaoui N, Mars M, Marrakchi M, Trifi M (2008). Characterization of Tunisian pomegranate (Punica granatum L.) cultivars using amplified fragment length polymorphism analysis. Sci Hortic 115:231-237.

Heidary S, Marashi H, Farsi M, Mirshamsi Kakhki A (2009). Assessment of genetic structure and variation of native Berberis populations of Khorasan provinces (Iran) using AFLP markers versus morphological markers. Iran J Biotechnol 7 (2):101-107.

Hurtado MA, Westman A, Beck E, Abbott GA, Llacer G, Badenes ML (2002). Genetic diversity in apricot cultivars based on AFLP markers. Euphytica 127:297-301.

Levin GM (1994). Pomegranate (Punica granatum L.) plant genetic resources in Turkmenistan. Plant Gene Res Newslet 97:31-36

Mantel NA (1967). The detection of disease clustering and a generalized regression approach. Cancer Res 27:209-220.

Mars M, Marrakchi M (1999). Diversity of pomegranate (Punica granatum L.) germplasm in Tunisia. Genetic Res Crop Evol 46:461-467.

Martinez L, Cavagnaro P, Masuelli R, Rodriguez J (2003). Evaluation of diversity among Argentine grapevine (Vitis vinifera L.) varieties using morphological data and AFLP markers. Plant Biotechnol 6(3):244-253.

Narzary D, Mahar KS, Rana TS, Ranade SA (2009). Analysis of genetic diversity among wild pomegranates in Western Himalayas, using PCR methods. Sci Hortic 121:237-242.

Nei M, Li W (1979). Mathematical model for studying genetic variation in terms of restriction endonucleases. Proc Natl Acad Sci USA 76:5269-5273.

Polanco C, Ruiz ML (2002). AFLP analysis of somaclonal variation in Arabidopsis thaliana regenerated plants. Plant Sci 162:817-824.

Rohlf FJ (1998). NTSYS-PC. Numerical taxonomy and multivariate analysis system, version 2.00. Exeter Software, Setauket, NY.
Rotondi A, Magli M, Ricciolini T, Baldoni L (2003). Morphologicaland molecularanalysisfor thecharacterization of a group of Italian olive cultivars. Euphytica 132:129-137.

Sanguinetti CJ, Dias Neto E, Simpson AJG (1994). Rapid silver staining and recovery of PCR products separated on polyacrylamide gels. Biotechniques 17:915-919.

Sarkhosh A, Zamani Z, Fatahi R, Ranjbar H (2009). Evaluation of genetic diversity among Iranian soft-seed pomegranate accessions by fruit characteristics and RAPD markers. Sci Hortic 121:313-319.

Sarkhosh A, Zamani Z, Fatahi R, Ebadi A (2006b). RAPD markers reveal polymorphism among some Iranian pomegranate (Punica granatum L.) genotypes. Sci Hortic 111:24-29.

Soriano JM, Zuriaga E, Rubio P, Llácer G Infante R, Badenes ML (2011). Development and characterization of microsatellite markers in pomegranate (Punica granatum L.). Mol Breeding 27:119-128.

Talebi Baddaf M, Sharifi Neia B, Bahar M (2003). Analysis of genetic diversity in pomegranate cultivars of Iran, using random amplified polymorphic DNA (RAPD) markers (in Farsi). In: Proc Third National Congress of Biotechnology, 2:343-345.

Tehranifar A, Zarei M, Nemati Z, Esfandiyari B, Vazifeshenas MR (2010). Investigation of physico-chemical properties and antioxidant activity of twenty Iranian pomegranate (Punica granatum L.) cultivars. Sci Hortic 126:180-185.

Torre A, Lopez C, Yglesias E, Cornelius JP (2008). Genetic (AFLP) diversity of nine Cedrela odorata populations in Madre de Dios, southern Peruvian Amazon. For Ecol Manage 255:334-339.

Vazifeshenas MR, Khayyat M, Jamalian S, Samadzadeh AR (2009). Effects of different scion-rootstock combinations on vigor, tree size, yield and fruit quality of three Iranian cultivars of pomegranate. Fruits 64(6):343-349.

Vos P, Hogers R, Bleeker M, Reijans M, Van de Lee T, Hornes M, Frijters A, Pot J, Peleman J, Kuiper M, Zabeau M (1995). AFLP: a new technique for DNA fingerprinting. Nucleic Acids Res 23:4407-4414.

Wen XP, Pang XM, Deng XX (2004). Characterization of genetic relationships of Rosa roxburghii Tratt and its relatives using morphological traits, RAPD and AFLP markers. J Hortic Sci Biotechnol 79:189-196.

Yuan Z, Yin Y, Qu J, Zhu L, Li Y (2007). Population Genetic Diversity in Chinese Pomegranate (Punica granatum L.) Cultivars Revealed by Fluorescent-AFLP Markers. J Geneti Genom 34(12):1061-1071.

Zahuang FY, Chen JF, Staub JE, Qian T (2004). Assessment of genetic relationships among Cucumis spp. by SSR and RAPD marker analysis. Plant Breed 123:167-172.

Zamani Z, Sarkhosh A, Fatahi R, Ebadi A (2007). Genetic relationships among pomegranate genotypes by RAPD markers and morphological characters of fruit. J Hortic Sci Biotechnol 82:11-18. 